\title{
CONCEPTUAL FOUNDATIONS OF IMPROVEMENT OF ECONOMIC REGULATION OF RATIONAL NATURAL RESOURCES USE IN MARKET CONDITIONS
}

\author{
Andrey Leonidovich Pozdnyakov \\ Southwest State University, Faculty of Building and Architecture, Kursk, Russia
}

The article is devoted to options for the economic regulation of environmental pollution. Possible types of damage caused to the environment, the concept of "external damage", its value are analyzed. Some principles are outlined for the development of an effective concept of the economic mechanism of nature management. It is noted that it is in the sphere of urban planning that an effective implementation of the economic mechanism of nature management is possible due to the territorial complexity of this type of activity. Reproduction of the environment as an integral part of the productive forces of society is a necessary condition for the continuity of the process of social reproduction. The study of the economic efficiency of environmental protection, both in the theoretical aspect and for management practice, involves solving complex problems of methodology and classification, as well as the development of appropriate methods and tools.

Key words: Ecology, Economic regulation, Nature management, Urban planning, Territorial planning

\section{INTRODUCTION}

All human activity, including economic, is carried out in a concrete material world, which is called the "environment". The study of the laws of human interaction with the environment is an absolute necessity both from the point of view of the survival of mankind and from the point of view of optimizing these interactions.

Currently, the problems of environmental protection, the rational use of natural resources, and ensuring environmental safety in their interrelation with the economy are increasingly being brought to the fore in the world. Obviously, the approaches to solving these problems both in the field of theory and at the level of economic practice in most countries are different. Recently, in economic science, the question is intensely debated: to what extent is the theory (with a modern system of categories) ready for solving new problems?

In economic theory, there is the notion of "external damage". This is the damage caused by economic agents in the process of their functioning to each other, as well as to the environment. Examples of such damage are pollution of atmospheric air and water bodies by harmful emissions (discharges), pollution of land and soil with solid, including household, waste, etc.

All these things are the types of damage caused by man to the environment in the course of human activities, as well as to the health of current and future generations of people. In fact, this is a certain type of economic costs, which must be minimized and reimbursed. Thus, in the course of a person's economic activity, not only values are created, but also damage that reimburses additional costs. Some authors call them "additional public costs", since the damage and costs of its reimbursement are borne by the whole society.
The damage to the environment and the social costs associated with it, in a market economy, usually do not appear as costs mediated in the market, so the classical and neoclassical economic theory until recently did not take them into account.

The environment is partly determined by natural conditions, in part is a product of human activity. Theoretical interpretation of economic problems arising in connection with environmental protection should probably include answers to questions: does the environment have value and, if so, what is the value of this cost?

\section{REPRODUCTION OF THE ENVIRONMENT AS ONE OF THE NECESSARY CONDITIONS OF NATURAL RESOURCES MONITORING}

Ecological and economic research over the past two decades in many countries around the world has practically proved that the cost of damage certainly exists. It is determined by the amount of socially necessary labor to protect and restore (improve) the environment, and it should include both the costs of eliminating (compensating) environmental violations, and the costs of their prevention. And if in the process of production or other activity a part of this value is destroyed (reduced), then it is absolutely natural that the lost value be reimbursed (reproduced).

The process of that reproduction is also a process of reproduction of the material elements of production, that is, the means of production, consumer goods and labor. From the point of view of the problems under consideration, it is important that among the means of production that must be reproduced is the environment, including its most important components - land, water, air and subsoil. Thus, the process of reproduction must simultane- 
ously imply the reproduction of the environment, which in this process is amortized.

The environment can be considered as an integral part of the productive forces of society, and its reproduction is a necessary condition for the continuity of the process of social reproduction. However, if the reproduction of the environment is included in the process of social reproduction, the value of the amortized or disturbed environment in the process of reproduction changes into the value of the produced goods (services), that is, becomes an integral part of its cost (as well as the cost of labor and means of production).

Reproduction of the environment, therefore, can to some extent be considered an analogy of the reproduction of the basic means of production. Reproduction of the environment, on the one hand, is a vital need, a necessary condition for the implementation of the production process as a whole, on the other hand, the provision of one of the basic human rights - the right to a favorable environment [01].

In the field of the economy, the reproduction of the environment is a major requirement, the implementation of which affects the production, distribution, consumption processes, which has a significant impact on the location of production facilities on a national scale and on many macroeconomic indicators.

The violation of these patterns on the part of producers leads in the long-term and medium-term (or even shortterm) perspective to the violation of the general economic process of reproduction and the gradual degradation of one of its elements - the environment, which is currently becoming a crisis.

At the same time, the current state of science and technology makes it possible not to limit reproduction only to the prevention and restoration of the environment, as it was at all times, but to improve it in the interests of man in such a way that it is not simple but expanded reproduction, i.e. meaningful improvement of the environment. Reproduction of the environment affects the policy of the state. To implement the state policy in the field of protection, reproduction and improvement of the environment it is necessary to develop and implement a number of programs and activities, including in the field of urban development.

Urban planning is the activity of state bodies, local self-government bodies, individuals and legal entities in the field of urban planning for the development of territories and settlements, determining the types of land use, design, construction and reconstruction of real estate objects, taking into account the interests of citizens, public and state interests, as well as national , historical, cultural, ecological and natural features of the territories and settlements (The Urban Development Code of the Russian Federation, 1998).

Accordingly, the objects of urban development are the territory of the Russian Federation (federal level), parts of the territory of the Russian Federation, the territory of the subjects of the Russian Federation (regional level), the territory of settlements, and other municipal entities (municipal level).

Thus, environmentally oriented urban planning involves a comprehensive solution of environmental problems of the territory at the federal, regional and municipal levels.

\section{ANALYSIS OF SOME APPROACHES TO ECONOMIC REGULATION OF ENVIRONMENT POLLUTION}

Among the existing approaches to determining the economic value of natural resources and natural services, which allow us to obtain a specific estimate, we can single out approaches based on: market valuation; Rent; Cost approach; Alternative cost; Of the total economic value (value). The most important question about the ecologization of the economy, the transition to a sustainable type of development is the question of the mechanisms for realizing such an environmentally oriented development. Here the priority is the formation of an effective economic mechanism for nature management. The following principles are outlined for the development of an effective concept of the economic mechanism of nature management:

1. An effective concept of rationalization and protection of the environment and an appropriate economic mechanism for nature management in sectors / complexes can be developed and implemented only after the development of a concept for the development of the sectors / complexes and the entire economy.

2. The economic mechanism of nature management should be an organic part of the "global" economic mechanism, it cannot be local, covering only the nature-exploiting sectors.

3. The economic mechanism of nature management in sectors / complexes should be formed on an intersectoral, intersectoral and interregional basis.

It is in the sphere of urban planning that an effective implementation of the economic mechanism of nature management is possible due to the territorial complexity of this type of activity.

Reproduction of the environment in the territorial context raises a number of particular questions, answers to which should be given both by economic theory and practice. First of all, the question arises of determining the extent (level) of damage and the costs of its prevention (compensation) in specific territories. Economic damage from environmental degradation (or environmental and economic damage) is understood as a monetary evaluation of negative changes in the environment as a result of pollution, in the quality and quantity of natural resources, and the consequences of such changes [02].

In other words, it is necessary to determine the costs of protecting and reproducing the environment. The definition of the above costs or damage is a complex method- 
ological problem and its correct solution is simultaneously the first step towards the development of an effective system of organizational, legal, economic and even political measures to regulate eco-urban development.

The second extremely important question is who should compensate for actual or possible damage. Does it have to be a producer - usually a specific culprit for the damage caused or the consumer for whom the goods and services are intended? Should this be the population of a particular city or region, or society as a whole?

The enterprise, as a rule, is not interested in voluntarily allocating additional funds for environmental protection. Proof of this is the usual practice, as well as the very state of the environment in cities and regions. These are measures that result in the elimination of, or at least as far as possible, the harmful impact of a particular economic entity on the environment, that is, the measures that ensure its reproduction.

Solving environmental problems increases the production costs of the enterprise as long as there is a direct link between production costs and prices for goods (services), which causes pressure on prices. Depending on the development of the situation on the market, this may in some way affect the profit of the enterprise, its profitability, which in turn may lead to a reduction in production and the number of jobs, other social consequences [03].

Let's consider the impact of costs on environmental protection on prices. Increasing the company's costs of protecting the environment affects its profitability and profit. There are two extreme cases:

- if an enterprise under given conditions and restrictions (state regulations, competition) cannot shift the increase in costs to consumers in the form of price increases, its profitability and profit will decrease;

- if an enterprise seeks to maintain this volume or the level of profit, it must raise prices.

In specific situations, both options are usually implemented. With a deeper analysis, it is also necessary to take into account the growth of labor productivity, changes in technology, etc. It should be added that the costs of protecting the environment and their impact on the profitability and profit of enterprises in different sectors of the economy vary significantly.

In the present conditions of economic development on an independent economic entity, an increase in these costs, if they correspond to the level of socially necessary costs, as in the classical market mechanism, leads to an increase in prices. However, the expected increase in prices in this case does not fully depend on the market element, but corresponds to the current needs and opportunities of the entire economy of the country, including forecasts (plans), pricing practice, and, in the main, accepted and current norms and rules for environmental protection and rational nature management.

At the same time, the facts show that enterprises have sufficient opportunities to compensate for the growth of environmental costs through increased labor productivity. In the future, however, the situation may change, as the cost of protecting the environment will grow faster than now, and the situation will become significantly more complicated as the market conditions become more complex and labor productivity growth reserves become depleted.

The relationship between the cost of environmental protection and the main indicators of the enterprise - prices, profitability, profit, etc. - they have not been studied enough, and they need to pay special attention to the analysis of environmental problems [04].

From the special nature of the modern economy, it follows that the possible consequences depend not so much on the spontaneous action of the market, as much on the actions of the management bodies. In accordance with the economic and environmental policy of the state, state authorities choose one or another possibility of environmental and economic "pressure" on enterprises, on the one hand, and take into account the needs of the economic and social development of the country or region, on the other.

If we consider the problem from the point of view of the distribution of gross domestic product (GDP) or gross national product (GNP) to the consumption fund and accumulation fund, it can be noted that environmental protection, on the one hand, contributes to GDP growth, and on the other hand, requires a certain share in its distribution. This means that if in the course of economic development a country usually allocates a certain share of GDP for accumulation, then the following two scenarios are possible:

- with an unchanged total investment fund, their increase in environmental protection will cause a reduction in investment in other sectors of the economy;

- while maintaining the total investment in other sectors of the economy, it is necessary to increase the overall share of accumulation to allocate funds for environmental protection.

The study of the economic efficiency of environmental protection, both in the theoretical aspect and for management practice, involves solving complex problems of methodology and classification, as well as the development of appropriate methods and tools.

Let's consider a fairly simple and most popular method - the "cost-benefit" analysis. This method can be considered a tool that allows public authorities to assess the real situations associated with the protection and formation (restoration and improvement) of the environment and make appropriate decisions by comparing costs (eliminating certain environmental violations or the need to improve a certain environmental situation) with the benefits that can be achieved as a result of the proposed activities. It is assumed that the implementation of the relevant proposals or projects is effective if the expected benefits are not less than the estimated costs. 
The issue of cost accounting in this method is not of particular interest, since they can almost always be determined with sufficient accuracy. It is more difficult to determine the benefits, as one of the significant "benefits" is to ensure ecological balance on our planet, and its preservation is a vital issue for humanity, in the solution of which one cannot rely on a market mechanism or various approximate estimation methods. In this connection, the "minimum task", which is vitally important, is to ensure simple reproduction of the environment, that is, the elimination of existing violations and prevention of possible damage.

In addition, public authorities when considering resource allocation issues (for example, federal or regional budgets), taxation, pricing for products of natural monopolies, etc., must increasingly take into account the requirements of expanded environmental reproduction.

Attempts are also known to use the method of structural analysis to study the economic interrelations and economic consequences of environmental protection, which makes it possible to implement a macroeconomic approach to the phenomena under study. This method makes it possible to visually fix various relationships and relationships between environmental costs and macroeconomic indicators such as GDP, GNP, capital investment, price level, etc., and, accordingly, the interrelationship between environmental issues (the need to address these problems) and the level of economic development of the country and the region [05].

Between the level of economic development and the quality of the environment there is not only a direct connection, but also feedback: the higher the level of development the country has achieved, the more urgent it is for the environment.

\section{CONCLUSION}

Economic instruments and urban policies are a priority of means and methods of regulation of environmental activities at the national, regional and local levels, along with the widespread introduction and use of new management tools of the anthropogenic impacts on the environment and natural resource management. A special place belongs to the methods of ecological and urban management of urban areas, optimizing the structure of the city economy, preservation (restoration) of the natural and the creation of natural and man-made landscapes, improving the use and improvement of recreational areas building, bringing to the standard level indicators of "environmental sustainability" of the territories and populations, environmental study of architectural and planning decisions, formation of ecological and urban development support programs, environmental zoning, etc.

\section{ACKNOWLEDGEMENT}

Author thanks the Rector of the Southwest State University, Doctor of Technical Sciences Yemelyanov S.G.

\section{REFERENCES}

1. Vladimirov V.V. (2000) The ecological imperative of the city // Industrial and civil construction, No. 9, pp.10-12.

2. Reimers N.D. (1992) Hopes for the survival of mankind. Conceptual ecology, $366 \mathrm{p}$.

3. Kuleshov A.S. (2000) Natural space - the basis for the development of the planning structure of the city // Industrial and civil construction, No. 1, pp. 33-36.

4. Pozdnyakov A.L, Samokhvalov A.M (2014) Urbanization and its impact on the ecology of cities and settlements: News of Southwest State University, №6 (57), pp. 74-78.

5. Pozdnyakov A.L, Pozdnyakova E.V (2016) The Main Trends in the Development of Industry in the Cities and Towns from the Position of Environmental Safety // International Journal of Applied Engineering Research, Volume 11, Number 23, pp. 11331-11334. 